\title{
Smoking cessation and periodontal health - a missed opportunity?
}

\author{
Abstracted from \\ Thomson WM, Broadbent JM, Welch D, Beck JD, Poulton R. \\ Cigarette smoking and periodontal disease among 32-year-olds: \\ a prospective study of a representative birth cohort. J Clin Periodontol 2007; 34: 828-834 \\ Address for correspondence: Murray Thomson, Department of Oral Sciences, School of Dentistry, \\ University of Otago, Dunedin, New Zealand. E-mail: murray.thomson@stonebow.otago.ac.nz
}

\section{Question: What is the association between long-term smoking and periodontal disease?}

\section{Design This was a cohort study.}

Cohort selection A longstanding prospective study was carried out of a birth cohort born in Dunedin (New Zealand) in 1972-1973.

Exposure measurement Periodontal examinations of the study participants were carried out when they reached the age of 26 and 32 years by calibrated examiners; smoking exposure was measured by questioning at ages 15, 18, 21, 26 and 32 years. Socioeconomic status (SES) was measured at the age of 26 years by categorising adult occupation using standard New Zealand occupation indices. Dental visiting behaviour was assessed by questioning at age 25 and 32 years.

Data analysis Chi-square tests were used to examine the statistical significance of differences observed with categorical dependent variables. Analysis of variance was used for continuous variables. Logistic regression modelling was used to examine smoking exposure and periodontitis prevalence and incidence while controlling for sex, SES, dental plaque accumulation and the use of dental services. Results Complete data were available for 810 individuals of whom $48.9 \%$ had smoked at some point $(31.5 \%$ were current smokers). Table 1 shows the prevalence, for a selection of smoking exposure groups of attachment loss at age 32 and the odds ratio compared with never-smokers and table 2 the incidence of $3+\mathrm{mm}$ attachment loss. Sites with $>5 \mathrm{~mm}$ attachment loss and were more likely to be incident cases after age 26 (OR, 5.2 and 3.2, respectively). Two thirds of new cases in individuals older than 26 years were attributable to smoking. There were no significant differences in periodontal health between never-smokers and those who had quit smoking after age 26 .

\begin{tabular}{l|c|c|c|c|}
\hline \begin{tabular}{l} 
Table 1. Prevalence of attachment loss at age 32 \\
\hline $\begin{array}{l}\text { Smoking } \\
\text { exposure } \\
\text { group }\end{array}$
\end{tabular} & \multicolumn{3}{|c|}{$\begin{array}{c}\text { More than 1 site with } \\
\mathbf{5 + m m} \text { attachment loss }\end{array}$} \\
\hline & No (\%) & No (\%) & OR* $^{*}$ & $\mathbf{9 5 \% ~ C l}$ \\
\hline $\begin{array}{l}\text { Smoked at } \\
\text { all ages }\end{array}$ & $95(11.7)$ & $28(29.5)$ & 7.13 & $3.53-14.38$ \\
\hline $\begin{array}{l}\text { Other age- } \\
32 \text { smokers }\end{array}$ & $160(19.8)$ & $39(24.4)$ & 5.68 & $3.06-10.54$ \\
\hline Never smoked & $414(51.1)$ & $18(4.3)$ & - & - \\
\hline
\end{tabular}

* compared with never smokers

\begin{tabular}{|c|c|c|c|}
\hline \multirow[t]{2}{*}{$\begin{array}{l}\text { Smoking } \\
\text { exposure } \\
\text { group }\end{array}$} & \multicolumn{3}{|c|}{$\begin{array}{l}\text { More than } 1 \text { site with } 3+\mathrm{mm} \text { attachment } \\
\text { loss increase }\end{array}$} \\
\hline & No (\%) & $\mathbf{O} \mathbf{R}^{*}$ & $95 \% \mathrm{Cl}$ \\
\hline $\begin{array}{l}\text { Smoked at all } \\
\text { ages }\end{array}$ & $27(28.4)$ & 5.16 & $2.73-9.76$ \\
\hline $\begin{array}{l}\text { Other age- } 32 \\
\text { smokers }\end{array}$ & $32(20.0)$ & 3.20 & $1.83-5.58$ \\
\hline Never smoked & $31(7.5)$ & - & - \\
\hline
\end{tabular}

Conclusions Current and long-term smoking in young adults is detrimental to periodontal health, but smoking cessation may be associated with a relatively rapid improvement in the periodontium.

\section{Commentary}

There is a lack of data from population-based prospective cohort studies on the relationship between smoking and periodontitis, especially as seen here, with this study's impressively high followup rates. ${ }^{1}$ This study used a complete birth cohort who had measures of periodontal status collected when participants reached the age of 26 and 32 years, with a very low dropout rate between the two examinations. The researchers use detailed measurements of tobacco usage collected over the previous 17 years. There were some weaknesses in the methodology and the interpretation of the data, however. As the authors point out, selfreporting of smoking is the only means of determining lifetime exposure and this can be subject to under-reporting, especially in younger age groups. Although biomarkers such as cotinine, a nicotine metabolite, can be used to determine current exposure, there is no equivalent for determining lifetime exposure. ${ }^{2}$ The use of partial-mouth periodontal examinations at 26 years will have underestimated the prevalence and extent of disease. In addition, the use of longitudinal partial measures to estimate changes between the ages of 26 and 32 years will have underestimated incidence of attachment loss and the effect of risk factors for disease. Nevertheless, the data clearly show that young adults who smoke an average of 15 or more cigarettes a day long-term will have worse periodontal health than nonsmokers.

The authors conclude that the data provide evidence of a beneficial effect of smoking cessation before people reach their mid-twenties. The finding that smoking cessation in young people before 
the age of 26 years results in similar levels of attachment loss as never-smokers at 32 years indicates that either the periodontium in younger adults has a greater potential for repair or that, by the age of 26 , this group of subjects had not smoked long enough or heavily enough to see differences. The latter suggestion is borne out by the finding that by the age of 26 the group who were still smoking by the age of 32 had almost double the mean pack-year score of the group who gave up by 26 years (9.3 versus 5.2 ). In addition the attachment loss scores at 26 years for the group that gave up smoking at 26 were already very similar to the never-smoker group. This supports the findings of other researchers who found that low levels of smoking had little effect on attachment and bone levels. ${ }^{3-5}$

The authors conclude that current and long-term smoking in young adults is detrimental to periodontal health and this is clearly demonstrated by their data. They also conclude that smoking cessation leads to rapid periodontal health improvement between the ages of 26 and 32 years: this is not borne out by the findings of this study. It is generally accepted that stopping smoking is beneficial for periodontal health, but there are few studies utilising the periodontal setting for promoting smoking cessation. Patients who opt for periodontal therapy attend regularly and clinicians effectively communicate treatment and self-care modalities. Additional health gain could be obtained by adding smoking cessation advice to periodon- tal treatment protocols, though there is a requirement for further high quality clinical trials to be undertaken to provide an evidence base for this intervention.

Penny Hodge and Viv Binnie

Dental School, Medical Faculty, University of Glasgow, Glasgow,

Scotland, UK

\section{Practice points}

- This study supports the theory that there is a relationship between progression of periodontitis and smoking in young adults who smoke more than an average of 15 cigarettes a day.

- Further research is needed to establish the benefit of smoking cessation advice in the dental setting for young adults.

1. Bergstrom J. Periodontitis and smoking: an evidence-based appraisal. J Evid Based Dent Pract 2006; 6: 33-41.

2. Scott DA, Palmer RM, Stapleton JA. Validation of smoking status in clinical research into inflammatory periodontal disease. J Clin Periodontol 2001; 28: 715-722.

3 Grossi SG, Zambon JJ, Ho AW, et al. Assessment of risk for periodontal disease. I. Risk indicators for attachment loss. / Periodontol 1994; 65: 260-267.

4. Grossi SG, Genco RJ, Machtei EE, et al. Assessment of risk for periodontal disease. II. Risk indicators for alveolar bone loss. J Periodontol 1995; 66: 23-29.

5. Martinez-Canut P, Lorca A, Magan R. Smoking and periodontal disease severity. / Clin Periodontol 1995; 22: 743-749.

Evidence-Based Dentistry (2009) 10, 18-19. doi:10.1038/sj.ebd.6400632 